\title{
MECHANICAL ENGINEERING DESIGN, DOES THE PAST HOLD THE KEY TO THE FUTURE?
}

\author{
Martin SOLE, Patrick BARBER and lan TURNER \\ The University of Derby
}

\begin{abstract}
Industry design of a complex product has always required a cross-disciplinary team of experts. Is it possible to mimic these teams in academia when training the design engineers of the future, and what disciplinary skills will they possess? The exceptional collaboration potential provided by the internet means industry experts can work as a team, and at the same time, reside anywhere in the world. What are the capabilities of teamwork when the team members may never see each other for real? Though a physical prototype is sometimes required, most prototypes are designed and created in the virtual world using 3D modelling. The model can be tested, checked for accuracy, have materials applied, and be created parametrically which allows the product's geometry to be reset to different sizes by the designer. Collaboration, effective communication, and 3D modelling make it possible to design intricate and complex designs remotely. While we rightly congratulate ourselves on the complexity of modern design and how clever we have become, we must not lose sight of past achievements. Design has become more complex in this modern age, but it would be incorrect to say that complex design did not exist in times past. Before the internet, aircraft were built, global communication systems existed, men went to the moon. What can we learn, if anything, by looking at the methods used to design complex products in the past? How can we apply what we learnt from the past to the future?
\end{abstract}

Keywords: Design, teams, past, future, industry, 3D modelling

\section{INTRODUCTION}

For over 50 years, Moor's law has been found true. The number of transistors that can be manufactured on an Integrated Circuit doubles approximately every 18 months [1]. The effect in computing terms is to produce ever more powerful computers, a new generation of faster computer hardware approximately every 18 months. These more powerful computers have allowed the development of more sophisticated software. In the early 1980's, to design a complex system required many thousands of two-dimensional drawings on paper, depicting three-dimensional parts. By the 1990's, as computing power increased it was possible, for the first time, to design a complex system, the Boeing 777 commercial aircraft, not on two-dimensional paper but using three-dimensional software [2]. The traditional design office was replaced with the design world. Geography no longer limited the designer's world. With the internet, complex designs could be produced with design teams who are never required to be in the same physical room. Physical mock-ups were no longer necessary, these could all be accomplished with the aid of computers. While we rightly pat ourselves on the back and say how clever we have become, let us take a few minutes to think of a time, before computers, when complex designs were still possible. Aircraft such as Concorde were designed without the aid of any computers. What can we learn about these 'ancient' methods that will assist us in our computer led design today? What can be learn from the past that will help us in training the design engineers in the future?

\section{INNOVATION OR INVENTION?}

Go back to the second century BC to meet Philo of Byzantium. Figure 1 is a reproduction of the earliest drawing of his force pump. All the essential principles are present. Water flows into the partial vacuum created by the upward motion of the piston, and on the down stroke, with the valves reversed, the water is forced up the pipe into the tank. This was a significant advance, or step change from anything that had gone before. This is considered a dynamic product as there is room for significant product development. This, it can be argued, was an invention. 
With most inventions, Philo's force pump was refined and next appears in the form of Hero's force pump (Figure 2.) from the first century AD, some 300 year later. The refinements which are most notable are the replacement of two pipes for conveying water to the tank into one pipe, the single actuation beam pivoting in the centre and the introduction of a nozzle. The dynamic product is now considered static, with very little scope for significant product development. Hero's force pump is an innovation based on Philo's invention [3].

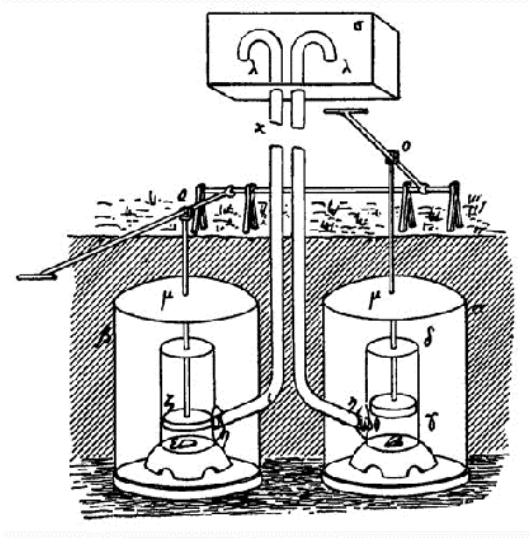

Figure 1. Philo's force pump [3]

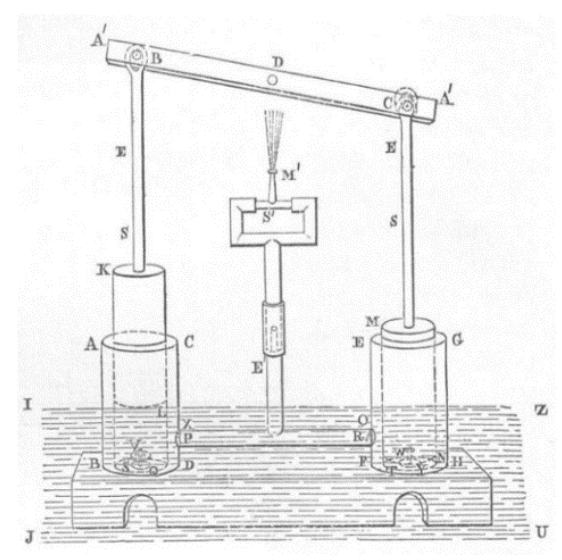

Figure 2. Hero's force pump [3]

Moving forward to the $18^{\text {th }}$ century when Newcomen developed the 'Atmospheric' Steam Engine [4]. Pumps that came before was based on Philo's and Hero's design and were limited to the strength of the

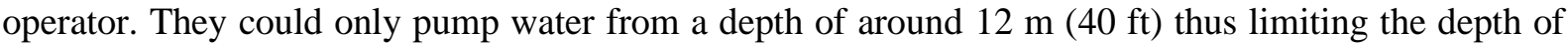
mining operations. With Newcomen's steam engine, water could be pumped from much greater depths even though its efficiency was only around $8-10 \%$. This was a dynamic product with room for significant improvement. This improvement came from James Watt's 1769 patented condenser which improved the efficiency of the steam engine to $12-14 \%$ which may not appear to be much but was a major step forward in technology [5].

Early designers probably passed on information by word of mouth. Later they saw the advantages of producing accurate, detailed sketches. Sketches are an important aid in idea generation and a way of piecing together unconnected ideas into design concepts. In our modern era, sketches have become scaled drawings and assist in providing missing data on dimensions and tolerances, and for simulating the operation of the product using 3D solid modelling [6]. Most students are adept at using computers and usually have little difficulty in using 2D and 3D Computer Aided Design (CAD) packages, but they do struggle to produce useful sketches [7]. The stepping-stone of sketching between an initial idea and developing it into a concept is an area that requires investigation.

The importance of a thorough literature review is demonstrated here. Hero carried out a literature review and found Philo's earlier design. The equivalent of a literature review in Hero's day involved travelling 
to the few sources of information available to him. The ancient library at Alexandria with its estimated 400,000 scrolls, or of ancient Rome with their earliest lending libraries [8]. How much effort does it take to carry out a thorough literature review? Most design today is not invention but innovation of an earlier design that is found by carrying out a thorough literature review. Do students with their many sources of information carry out a thorough literature review? To be thorough requires researching areas that may appear completely unrelated to the planned design project. To illustrate, a well-known brand of washing powder advertise that it cleans using the power of oxygen. This appears to be a rather spurious claim. While researching, would it be obvious to research fishing boats, no, even though fishermen for years have put their dirty clothes in a net over the rear of the boat. The churning of the propeller releases oxygen which cleans the clothes. Something totally unrelated to washing powder, fishing boats, provided a valuable clue to the researcher. Do students appreciate the importance of such a review? Are they taught how to carry a thorough review?

\section{THE R100 AND R101}

Moving forward to the $20^{\text {th }}$ Century. On 24 August 1921, the airship R38, with a crew of 49 on board was practicing turning trials over the Humber Estuary. This involved turns at full helm and full speed. It suffered structural failure and broke in two, killing 44. During the subsequent investigation it came out that responsible officials had made no calculations whatsoever of the aerodynamic forces acting on the ship in flight. No one was sacked over it, or even suffered censure. This same team was entrusted later to the building of the R101, see Figure 3.

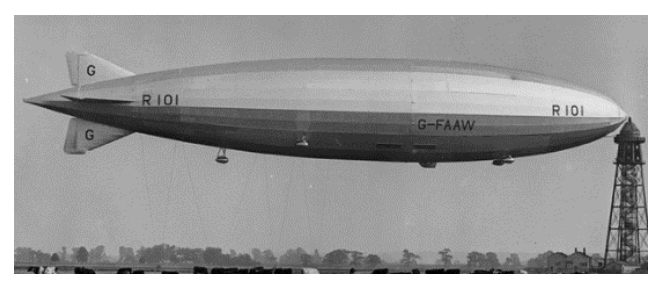

Figure 3. $R 101$ [9]

In 1924 a team was put together to begin design on another airship, the R100. The team was led by Mr. B.N. Wallis, made famous later during World War 2 for designing the Wellington Bomber, the bouncing mine that destroyed the great dams of Germany, and finally some of the largest bombs of the war, Tallboy (6 tons) and Grand Slam (10 tons). This small team used a pair of 'Calculators', specialists specifically employed to determine the stresses acting on the airship frame. This could take up to 2-3 months and began by estimating the forces in the frame, then re-calculating the forces until a satisfactory resultant of zero was obtained. The final check was made by determining the horizontal and vertical forces throughout the frame, and if the calculations were correct, they too would give a resultant of zero. These hand calculations would fill 50 pages of foolscap [10]. This airship during its trial flights proved to be a successful and safe airship. The R100 clearly demonstrates the importance of stress calculations followed by re-calculations using different but complimentary methods until satisfactory results are obtained.

Let us now return to the R101.The work on it was finished on the $12^{\text {th }}$ October 1929. Two days later it slipped from the mast at Cardington, United Kingdom, on its maiden flight. After several flights it was decided that the lifting capacity of the airship required increasing, and at the same time to initiate as much weight saving as practical. Were these major changes due to a lack of pre-manufacture calculations? The decision was made to insert an extra section in the centre of the airship which would increase the length by $53 \mathrm{ft}$ from $724 \mathrm{ft}$ to $777 \mathrm{ft}$. The gross lift had been increased to 167.2 tons, with the fixed weight now 117.9 tons, giving 14.4 tons increase in disposable lift to 49.3 tons [11]. After brief trials and a Certificate of Airworthiness that was issued just before departure, the airship left for a journey to India. In poor weather it made it just south of Beauvais, France where is crashed killing 48 out of a compliment of 54 .

The two tragedies of the R38 and R101, both designed by the same team which was known to be lacking in producing accurate or any calculations, highlights the importance of applying correct mechanical principles during a design project. Today, software provides many opportunities to determine the stress, 
strain, and deflection of a component. 3D modelling with Finite Element Analysis (FEA) can, in a fraction of the time, produce results that the engineers working on the airships could only dream of [12]. But much more is required. Using 3D modelling software is not difficult to learn. Understanding its limitations takes much longer. Students must be aware of the requirement to validate the setting up of the software so that correct results are obtained. SolidWorks, a 3D modelling supplier provides 142 validation examples to help the user understand these limitations [13].

To back up modern day FEA simulations, calculations based on accepted industry calculations are also necessary. When the R100 was in its design stage, 'Calculators' spent months calculating the effect of forces acting on the airship frame. They backed up their calculations by checking them using a different set of equations. Do we teach our students to do likewise? They usually have enough difficulty using one set of equations and getting them to match the results from FEA. When they do not match, which is right, and which wrong? The more methods students understand and can use to calculate stress the more accurate will be their results. As an example, a basic, but extremely important calculation is that of stress in beams. What methods are they taught? Macaulay's, Castigliano's, Superposition, and Elastic Energy. Any or all these methods can be used to determine the stress in a beam, then recheck it and finally to confirm the results using a validated FEA method.

\section{CONCORDE}

The design and manufacture of Concorde (Figure 4.) was an early example of international cooperation. On the $5^{\text {th }}$ November 1956 the first of 7 meetings took place of the Supersonic Transport Aircraft Committee. Several technical subcommittees each had 12 meetings, Air Registration Board, Aircraft Research Association, National Physical Laboratory, and College of Aeronautics. Finally, Specialist Working Groups met many times. By $29^{\text {th }}$ November 1962, the historic Anglo-French Agreement to build Concorde was signed [14]. This agreement provided details of the responsibilities each country was to assume. Five main areas of equal sharing were stipulated, Structure, Systems, Aerodynamics, Strength and aero-elasticity calculations, and Weight and Centre of Gravity estimates. Later, the aircraft ancillary systems were allocated to each country. A 50/50 split was the aim. As an example, the hydraulic pumps were designed and manufactured separately by both countries to eliminate the possibly of both countries' pumps having the same fault, if any.

Nothing like Concorde had ever been attempted before. The technical problems were immense. All parts were designed using 2D systems to represent 3D parts. Only the most basic computer systems existed, so nearly all calculations were carried out manually. The designers could only dream of Finite Element Analysis (FEA) and virtual mock-ups. Therefore, as Mr. James Hamilton, the Director-General (Concorde) at the Ministry of Aviation said 'This airplane was the most tested airplane of all time. We had rigs for everything.... we were putting all the systems together under real flight conditions for the first time, you can never be quite sure' [14].

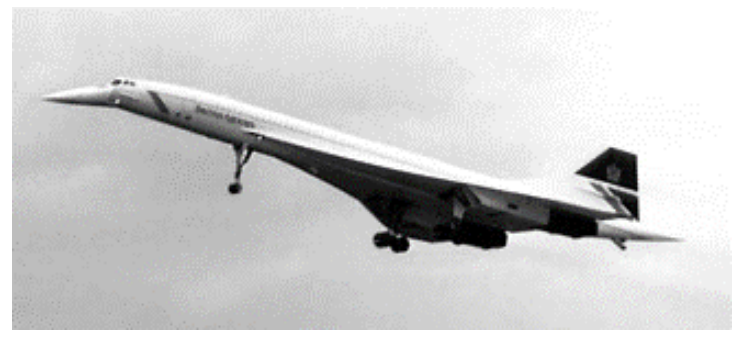

Figure 4. Concorde

The effect of coordinating the United Kingdom and France's input, designing, and then redesigning, inflation, devaluation, changes in exchange rates, testing, flight testing was shown clearly in the increasing costs. In 1962 the estimated cost was $£ 150-170 \mathrm{~m}$. By 1979 the estimated cost had spiralled to $£ 1129 \mathrm{~m}$.

Concorde is an example of teamwork and cooperation between two countries. Regular meetings were held, and clear lines of responsibilities decided upon. The design was world leading which made the development costs extremely high. Software FEA simulation was not an option the Concorde designers had. Even if software FEA simulation was available, it would not have helped with the problems the designers were facing. Software FEA simulation is very good for known problems, problems that the 
computer programmers could include, but no good for cutting edge design. When teaching design to students, it is vital that they understand fully the software they are using, but more important, its limitations.

\section{BOEING 777 -THE COMPUTER AGE}

The designers and manufacturers in early aircraft builds at Boeing were around 50 yards apart from each other. As the scale of the company grew, little enclaves developed. Structures went in one place, air conditioning another. The culture of the company became 'Us and them'. Earlier aircraft builds could have around 100,000 parts produced on 2D drawings. Various mock-ups were produced, growing in complexity, to check that all the different parts would fit together.

When the planning to design and build a new aircraft, the Boeing 777 (Figure 5), it was decided this culture had to change. Design-Build Teams brought specialists together, manufacturing, tooling, planning, engineering, finance, materials etc.

For the first time, computers were powerful enough to design 3D parts virtually. Computer-graphics Aided Three-dimensional Interactive Applications (CATIA) format was used. These virtual parts could then be assembled using a second program, Electronics Preassembly in the CATIA (EPIC). Boeing distributed 2,200 computer terminals among its design team. All this was connected to the world's largest grouping of IBM mainframe computers (8 off). This system allowed manufacturers in Japan, engine makers in the United States of America and the United Kingdom immediate access to the data.

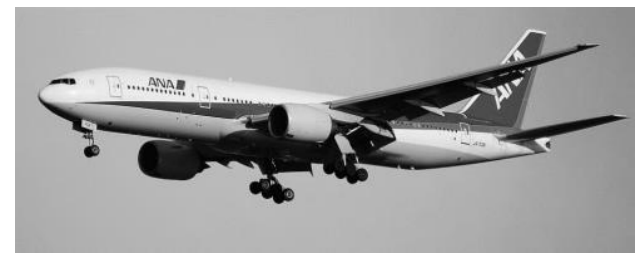

Figure 5. Boeing 777 [15]

During the planning phase, justification for the use of a very expensive computer system to design the aircraft was required. The planners looked back at a previously manufactured aircraft, the Boeing 767 . They concentrated on certain aspects of its design such as the doors. On this aircraft there was two doors, passenger, and cargo. The doors, during the design phase required 1,341 modifications. The planner's put a dollar value on these modifications and came to a staggering total of $\$ 64$ million. To put this amount in context, a new Boeing 767, back in the 1970's cost $\$ 100$ million. When the doors on the new Boeing 777 were designed by two DBT's using the new CATIA and EPIC systems the errors were reduced by $95 \%$ which also equates to similar financial savings. Another example was using CATIA and EPIC to check 20 pieces of the flap system. The computer ran 207,601 checks for interferences between parts. A total of 251 interferences were highlighted. These were printed out and at the next DBT meeting it was decided who would be responsible for which interference, saving any possible duplication.

The importance of modern computer systems is emphasized by the Boeing 777 design and manufacture. Today the CATIA and EPIC systems are combined into one system making for even more savings. The importance of design being a team operation was shown by using Design-Build Teams [2].

\section{CONCLUSIONS}

Looking through this brief history of designing complex components it becomes clear that our ability to design complex systems with relative simplicity was built on the shoulders of design engineers who were giants in their fields. Philo's and Hero's Force Pump reminds us of the importance and simplicity of communication using sketches. Can computers compete with pencil and sketch pad? Not yet, but this could be an area for development. To get the most benefit from a literature review, be thorough and think 'outside the box'. The crashes of the R101 and R38 demonstrate what could happen when designing an airship, with little to no calculations. Compare them with the successful R100, where the stresses were fully calculated, and the importance of double-checking calculations. Does the reliance of students on 3D modelling and FEA need to be reduced and manual calculations increased? Concorde's technical design, which still marvels today, must be weighed with the astronomical costs involved in 
testing and proving. The collaboration between two countries in a design and manufacture project identify the importance of regular meetings, and clear allocation of responsibilities. The beauty of 3D modelling and the advantages in time and money that the Boeing 777 benefited from. Are skills required to successfully work in a team being developed in students?

We do not have to invent something new to improve the way we design. By looking in the past and reminding ourselves about things already proven to work we can improve our designs for the future. Old processes may require a little innovation to bring them into the modern world, but the benefits should be clear.

\section{REFERENCES}

[1] Swan C. (2020) 55 th Anniversary of Moor's Law. [online] Available from: https://www.infoq.com/news/2020/04/Moores-law-55/ [Accessed 26 December 2020].

[2] Sabbagh K. (1996) $21^{\text {st }}$ Century Jet. The Making of the Boeing 777. Pan Books. London, United Kingdom.

[3] Hurst K. (1999) Engineering Design Principles. Arnold. London, United Kingdom. ISBN 0340 598298.

[4] White A. (2014) Early Newcomen Engines on the Warwickshire Coalfield, 1714-1736. [online] Available from: https://doi.org/10.1179/tns.1968.017 [Accessed 8 January 2021].

[5] Selgin G. and Turner J. (2020) Strong Steam, Weak Patents, or the Myth of Watt's InnovationBlocking Monopoly Exploded. [online] The Journal of Law and Economics. Available from: https://www.journals.uchicago.edu/doi/abs/10.1086/658495 [Accessed 8 January 2021].

[6] Dieter G. and Schmidt L. (2009) Engineering Design. $5^{\text {th }}$ Ed. McGraw-Hill. New York, United States of America. ISBN 978-0-07-339814-3.

[7] Stroud I. and Hildegarde N. (2011) Solid Modelling and CAD Systems. How to Survive a CAD System. Springer-Verlag, London. DOI 10.1007/978-0-85729-259-9.

[8] Casson L. (2002) Libraries in the Ancient World. Yale University. United States of America. ISBN 0-300-09721-2.

[9] The National Archives. (2020) R101 Airship Disaster. Available from: https://www.flickr.com/photos/nationalarchives/5078097097/in/photolist-8JJzmx-8JJzmk8JJzme-8JJzmr-8JLUEm-5AMLus [Accessed 29 December 2020].

[10] Shute N. (1956) Slide Rule - The Autobiography of an Engineer. Readers Union William Heinemann.

[11] Stewart S. (1994) Air Disasters - Dialogue from the Black Box. The Promotional Reprint Company Limited. Australia. ISBN 1856481824.

[12] Hutton D. (2004) Fundamentals of Finite Element Analysis. McGraw-Hill. New York, United States of America. ISBN 0-07-239536-2.

[13] SolidWorks Simulations (2019) SOLIDWORKS Simulation 2019 Validation. Available from: https://www.solidworks.com/sites/default/files/2019-04/VPCS-English2019.pdf [Accessed 30 December 2020].

[14] Owen O. (2001) Concorde, Story of a Supersonic Pioneer. NMSI Trading Ltd, Science Museum, London ISBN 1900747421.

[15] Pixabay (2015) Boeing 777 Ana All Nippon Airways. [online] Available from: https://pixabay.com /photos/boeing-777-ana-all-nippon-airways-876098/ [Accessed 2 January 2021]. 